\title{
UAV Multispectral Imagery Can Complement Satellite Data for Monitoring Forest Health
}

\author{
Jonathan P. Dash ${ }^{1, *}$, Grant D. Pearse ${ }^{1}$ and Michael S. Watt ${ }^{2}$ \\ 1 Scion, 49 Sala Street, Private Bag 3020, Rotorua 3046, New Zealand; grant.pearse@scionresearch.com \\ 2 Scion, 10 Kyle St, P. O. Box 29237, Christchurch 8440, New Zealand; michael.watt@scionresearch.com \\ * Correspondence: jonathan.dash@scionresearch.com
}

Received: 17 June 2018; Accepted: 1 August 2018; Published: 3 August 2018

\begin{abstract}
The development of methods that can accurately detect physiological stress in forest trees caused by biotic or abiotic factors is vital for ensuring productive forest systems that can meet the demands of the Earth's population. The emergence of new sensors and platforms presents opportunities to augment traditional practices by combining remotely-sensed data products to provide enhanced information on forest condition. We tested the sensitivity of multispectral imagery collected from time-series unmanned aerial vehicle (UAV) and satellite imagery to detect herbicide-induced stress in a carefully controlled experiment carried out in a mature Pinus radiata D. Don plantation. The results revealed that both data sources were sensitive to physiological stress in the study trees. The UAV data were more sensitive to changes at a finer spatial resolution and could detect stress down to the level of individual trees. The satellite data tested could only detect physiological stress in clusters of four or more trees. Resampling the UAV imagery to the same spatial resolution as the satellite imagery revealed that the differences in sensitivity were not solely the result of spatial resolution. Instead, vegetation indices suited to the sensor characteristics of each platform were required to optimise the detection of physiological stress from each data source. Our results define both the spatial detection threshold and the optimum vegetation indices required to implement monitoring of this forest type. A comparison between time-series datasets of different spectral indices showed that the two sensors are compatible and can be used to deliver an enhanced method for monitoring physiological stress in forest trees at various scales. We found that the higher resolution UAV imagery was more sensitive to fine-scale instances of herbicide induced physiological stress than the RapidEye imagery. Although less sensitive to smaller phenomena the satellite imagery was found to be very useful for observing trends in physiological stress over larger areas.
\end{abstract}

Keywords: tree health; precision forestry; sensor fusion; RPAS; drone; RapidEye; plantation forest; radiata pine; forest management; forest productivity

\section{Introduction}

Highly productive plantation forests are required to meet the timber and fibre demands of the Earth's population in a sustainable manner. A significant research effort is focussed on maximising the returns from global forest plantations through silvicultural practices [1,2], tree breeding programmes [3,4], improving forest nutrition [5], and developing remote sensing methods to enhance forest management [6-8]. Yields from intensively managed monoculture plantations face significant threats from unwanted organisms, the impact of extreme weather events, and increasingly from the adverse effects of air pollution $[9,10]$. The frequency and severity of losses associated with these factors are expected to increase in many regions as the effects of climate change become more severe [11]. Tools to detect, quantify, and help mitigate the impacts of these damaging biotic and abiotic factors are essential for maximising plantation forest yields. In recent years, significant progress has been 
made towards the detection and monitoring of pests and diseases in trees and forests. These methods often use remote sensing and ground assessments to detect signs and symptoms of a stressor [12]. Surveillance procedures are required for a range of spatial scales to detect incursions and to inform effective forest management to mitigate negative effects on tree growth and the probability of tree mortality $[13,14]$.

Since the advent of civilian Earth-observing satellites suitable for vegetation monitoring, a significant body of research has used satellite imagery to quantify the spatial extent of insect outbreaks and tree mortality at regional and landscape scales using moderate $(5-30 \mathrm{~m})$ and coarse $(\geq 30 \mathrm{~m})$ resolution imagery [15-18]. More recently, research has established the utility of high-resolution $(\leq 5 \mathrm{~m})$ satellite imagery [19-21] and imagery collected from manned aerial platforms [14,22,23] for monitoring tree health. This research has shown that sensors with finer spatial resolution offer greater accuracy for detecting and monitoring disease expression. This is especially true for early-stage outbreaks or those with a limited spatial extent that may only be apparent at the sub-stand or individual tree level.

Unmanned aerial vehicles (UAVs) have emerged as a useful data source applicable to many forest management scenarios [24]. A growing number of studies have examined the use of UAVs for a wide range of applications including forest measurement [25-30], informing silvicultural practice [31,32], forest health monitoring [12,33-35], and monitoring events such as fires [36,37], wind damage [38], and harvesting [39]. The cost of these platforms and associated sensors are rapidly decreasing while their capabilities and sophistication are constantly improving. There are several appealing aspects of UAVs including greater flexibility due to ease of deployment and transportation, ability to capture extremely high resolution data, and the capacity to capture useful imagery even in the presence of cloud cover. UAVs cannot rival traditional platforms in terms of spatial extent; however, with appropriate processing and analysis frameworks, data from UAVs are likely to offer substantial opportunities to augment and enhance data collected from these more traditional platforms.

A few studies have sought to develop methods linking UAV data and satellite imagery to provide an enhanced data product with utility beyond that of the component datasets. Imagery collected from UAVs has been used to calibrate measures of burn severity derived from Landsat 8 imagery following a wildfire with some success [40]. UAV imagery has also been used to augment satellite imagery to inform land managers about compliance with resource management policy in riparian habitats. The UAV imagery enhanced both the temporal and spatial resolution of the satellite imagery providing an effective tool for monitoring compliance and for conservation of endangered habitat [41]. A study based in Sumatra [42] used a combination of Landsat and UAV imagery to monitor orangutan habitat. The UAV data were used to train classification algorithms applied to Landsat data to differentiate land use classes (oil palm plantation vs. reforestation vs. logged forest) relevant to orangutan conservation with considerable success (classification accuracy over 75\%) [42]. In a similar manner, a study conducted in a Costa Rican ecological reserve used UAV data to identify land cover classes and then applied these to a historical archive of Landsat data [43]. Methods have been proposed for integrating imagery from the European Space Agency's Sentinel-2 satellites with UAV data for forest inventory purposes. In the aforementioned study, a hierarchical, model-based mode of inference was used to provide viable population estimates and corresponding uncertainties based on datasets with differing spatial coverages [44]. Initial methods have also been developed to extrapolate UAV data on tree measurements using imagery from the Pléiades satellite constellation [45].

Change detection techniques provide a valuable starting point for the identification of subtle changes in forest health based on the spectral information. The aggregation of multi-temporal images can greatly improve the signal-to-noise ratio [46] and the use of longer time periods can mitigate the confounding impacts of environmental factors such as cloud cover on detection. Using this technique, acceptable accuracies have been demonstrated for the detection of bark beetle attack on conifer species [47-50] and needle discolouration resulting from Dothistroma pini [14]. Analysis of time-series satellite imagery was used by Eitel et al. (2011) who chainsaw girdled patches of piñon-juniper woodland and then successfully monitored the induced tree stress before mortality 
using a dense sequence of multispectral images from the RapidEye (Planet, San Francisco, USA) satellite constellation [51]. Invoking physiological changes in this manner provides superior experimental control and is well suited to testing and calibrating methods for the early detection of symptoms such as pathogen-induced physiological changes in foliage. In a similar fashion, Dash et al. [12] injected herbicide into the stems of mature plantation trees and tracked changes in canopy colour and density using time-series multispectral UAV imagery. This study [12] confirmed the utility of high-resolution, time-series UAV data for monitoring physiological stress in trees and identified suitable spectral indices for this task. However, these findings were limited to small areas due to the limited data collection capability of UAV platforms. Further research was required to investigate whether widely-used satellite imagery products could be used as a complementary data source to expand the detection of physiological stress to larger areas.

In this study, we investigated the utility of UAV and satellite multispectral imagery for detecting physiological stress in forest trees and sought to define the detection capability. To accomplish this, we developed methods to link UAV and satellite data for detection of physiological stress and tested whether these could provide increased area coverage and models with greater predictive power than either dataset alone. We hypothesised that very high resolution UAV imagery collected with a narrow-band multispectral camera could provide greater predictive capability for detecting tree stress than broad-band satellite imagery. We also tested whether differences in sensitivity were associated with differences in the spatial or spectral resolution of the sensors.

\section{Methods}

The study site, experimental treatment, and field data were the same as reported in [12]. The essential details are reproduced here for convenience.

\subsection{Study Site}

As described in [12], the study site was located in Kinleith Forest in New Zealand's Central North Island (Figure 1) (Latitude $38^{\circ} 24^{\prime} 18.74 \mathrm{~S}$, Longitude $176^{\circ} 0^{\prime} 59.28 \mathrm{E}$ ), approximately $28 \mathrm{~km}$ south-east of the town of Tokoroa. The site elevation is approximately $230 \mathrm{~m}$ and slopes gradually up towards the south-eastern corner of the trial. The site experiences a temperate maritime climate (total annual rainfall $=1238 \mathrm{~mm}$, mean annual temperature $=13.4{ }^{\circ} \mathrm{C}$ ) and the soils are loam belonging to the Kairanga series [52]. The trial area of interest was 2.7 ha and was located within a 7.3 ha stand of Pinus radiata D. Don (P. radiata) planted in July 1993. Site preparation was via V-blading and the site was in its second rotation under plantation forest. Stand density at planting was 635 stems $/$ ha $(4.5 \mathrm{~m} \times 3.5 \mathrm{~m})$. No thinning was undertaken and trees that suffered mortality early in the rotation were replaced. The site contained 35 rectangular $(0.04 \mathrm{ha})$ plots that were part of a now defunct fungicide spray trial into disease resistance in immature trees. The fungicide spray trial was completed before age 6 (1999) whereafter the trees were left to grow. At the initiation of this study, a comprehensive health survey of the site showed no evidence of disease expression and the majority of trees were in good health. The study trees were mature and large (mean diameter at breast height $=462 \mathrm{~mm}$, mean top height $=43.5 \mathrm{~m}$ ) at the time of data collection and were harvested soon after the conclusion of this research.

\subsection{Experimental Design}

The existing trial layout and plots were used to distribute the experimental treatments throughout the study area. These were used because they were clearly demarcated and accurately mapped, making design and navigation simple. Of the 35 plots five plots were randomly assigned to each of 6 treatments (Table 1), with the remaining 5 plots were excluded from the trial. All plots were rectangular and contained 35 trees in seven rows planted with a spacing of $3.5 \times 4.5 \mathrm{~m}$. Trees that were dead or severely suppressed were not included in the trial. The mean number of dead, severely suppressed, or missing trees per plot was 5.79 (range $=2-11)$. The experimental treatment defined the size of the cluster 
(groups of treated trees) that were poisoned to cause physiological stress and simulate the symptoms that might be expected during a disease outbreak. The objective of using different sized clusters was to investigate the sensitivity of different remotely sensed datasets to different levels of physiological stress as might be associated with certain diseases. Study trees were treated with Metsulfuron methyl in the form of water-dispersible granules at a rate of $200 \mathrm{~g} / \mathrm{L}$. This mixture was injected through holes drilled into the tree stem. Holes were drilled $25 \mathrm{~cm}$ apart around the circumference of each stem and $15 \mathrm{~mL}$ of herbicide was deposited into each hole. In total, 13.32 L of Metsulfuron mixture was applied to the study site. Administration by injection was used as it allowed for carefully targeted application and because expert advice indicated it would invoke changes in foliar colour and retention within the duration of the study. Herbicide application was completed for all trees in a single day on the 3 December 2015 [12].
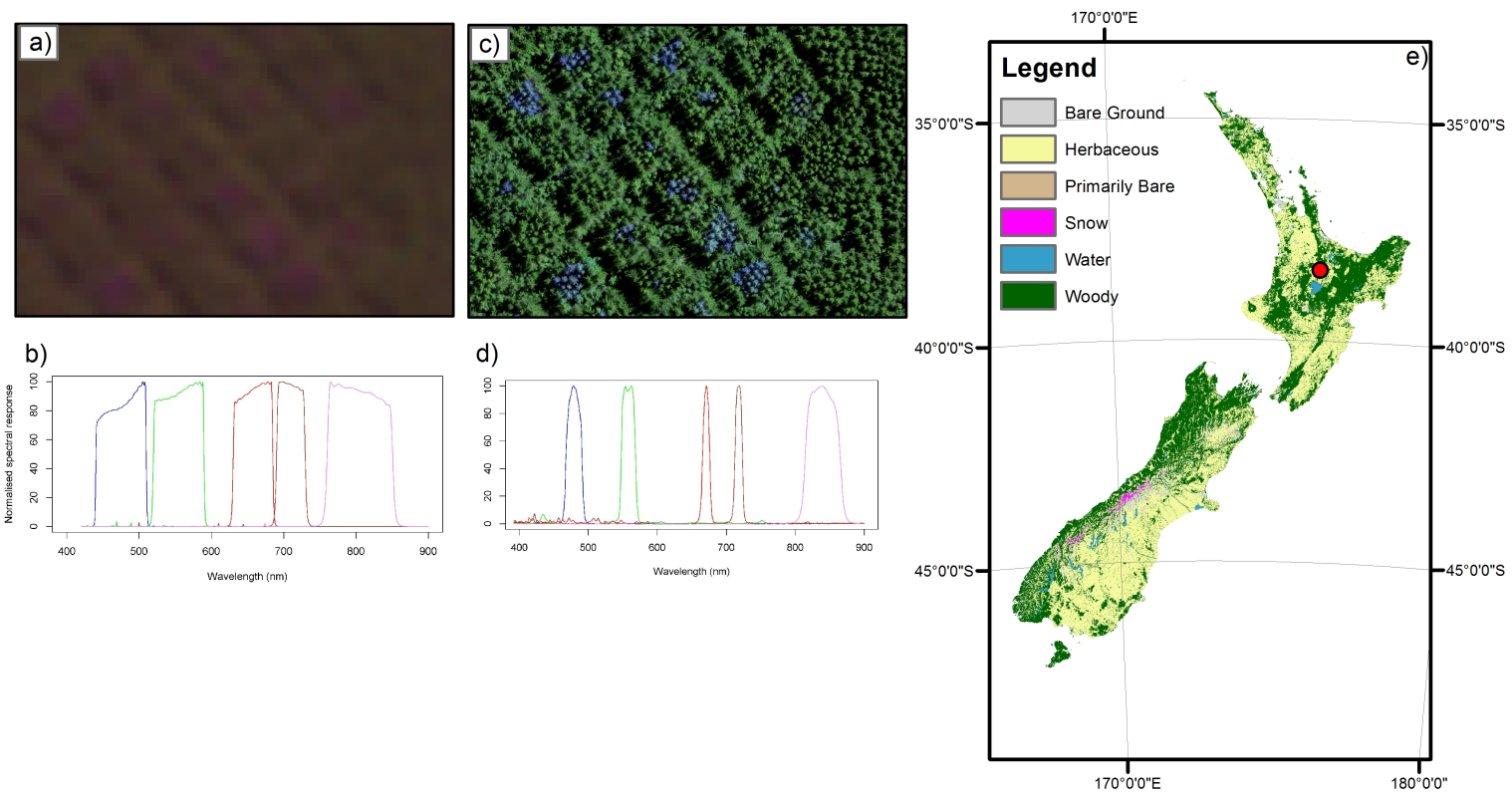

Figure 1. Location of the study site within New Zealand with examples of the broadband multispectral imagery from RapidEye (a) and the UAV MicaSense Red Edge camera (c) with both images showing the trial area at a 1:5000 scale. The normalised spectral response curves for the RapidEye (b) and the MicaSense RedEdge (d) sensors are also shown based on data provided by the sensor developers.

Table 1. Experimental treatments used in the study. The number of trees subjected to herbicide application in the treatment and the mean cross-sectional area occupied by the canopy of the treated trees is shown. This table is modified from [12].

\begin{tabular}{cccc}
\hline Treatment & Description & $\mathbf{n}$ & Area $\mathbf{( m}^{\mathbf{2}} \mathbf{~}$ \\
\hline 0 & Control, no trees poisoned & 0 & 575 \\
1 & Single tree closest to plot centre is poisoned & 1 & 18 \\
2 & Two trees closest to the plot centre poisoned & 2 & 30 \\
3 & Four trees closest to the plot centre poisoned & 4 & 77 \\
4 & Eight trees closest to the plot centre poisoned & 8 & 126 \\
5 & Sixteen trees closest to the plot centre poisoned & 16 & 279 \\
\hline
\end{tabular}




\subsection{UAV Imagery}

The UAV dataset used in this study was originally described in [12]. A co-axial quad-copter UAV was used for all data collection. The craft was a modified version of the Aeronavics (Aeronavics, Raglan, New Zealand www.aeronavics.co.nz) SkyJib heavy-lift airframe. This craft had a flying time of around $15 \mathrm{~min}$. with a payload of approximately $5 \mathrm{~kg}$ and provided a stable platform even in strong, turbulent winds. A single flight plan was used for all data collections to minimise variance associated with campaign settings. The flight plan used 18 flight lines to cover the area of interest and ensured that all craft manoeuvres and altitude adjustments occurred outside of the study area to minimise flight-related artefacts in the data collected. The original intent was to collect imagery on a weekly basis as the weather conditions permitted. In the end, data collection was significantly sparser due to technical difficulties and poor weather resulting in nine separate acquisitions between 30 October 2015 and 3 March 2016.

A series of nine ground control points (GCPs) were established around the study area and fixed using a Trimble Geo7X GNSS receiver (Trimble Navigation Ltd., Sunnyvale, CA, USA). Positions were differentially corrected using a network of local continuously operating reference stations maintained by Land Information New Zealand (LINZ). The targets established at the ground control points were easily manually identified in the multispectral imagery. The GCPs were used to accurately georectify all UAV imagery [12].

Narrowband multispectral imagery was collected using a MicaSense RedEdge 3 camera (Micasense, WA, USA). The camera provides imagery in five narrow bands (blue $=455-495 \mathrm{~nm}$, green $=540-580 \mathrm{~nm}$, red $=658-678 \mathrm{~nm}$, red edge $=707-727 \mathrm{~nm}$ and near-infrared $=800-880 \mathrm{~nm}$ ) (Figure 1) via five separate imaging units that operate nearly simultaneously. The camera has a lens focal length of $5.5 \mathrm{~mm}$ and field of view of $87.4^{\circ}$. The camera was housed in a gimbal to ensure nadir orientation of the camera during data collection. The flight plan ensured cross-track and along-track overlap of $85 \%$ and a calibrated reflectance panel was imaged directly before and after each flight and used for reflectance calibration using the empirical line method [53]. The UAV imagery was collected from a flying altitude of approximately $90 \mathrm{~m}$ above the local terrain and resulted in a ground sample distance (GSD) of $6 \mathrm{~cm}$. Imagery acquisition was limited to within two hours either side of local solar noon to minimise shadows.

The imagery was exported from the MicaSense RedEdge 3 in 12-bit RAW format. These images were mosaicked into a single, multi-band image covering the entire study area. The raw digital numbers (DNs) were converted into reflectance values using the calibrated reflectance panel. The relationship between DNs and the natural logarithm of the image surface reflectance is linear and the y-intercept can be interpreted as the minimum surface reflectance that can be detected for each wavelength band [53]. This can then be used to develop a regression equation to convert DNs to reflectance values using a calibration equation [54]. Images were georectified using the GCPs recorded within the study site and visible in the imagery [12].

\subsection{Satellite Imagery}

RapidEye is a constellation of Earth-observing satellites that provide sun synchronous imagery from an orbit height of $680 \mathrm{~km}$ with a swath width of $77 \mathrm{~km}$ and a 5 day revisit time. RapidEye imagery has a spatial resolution of $5 \mathrm{~m}$ and provides data in 5 broad bands (blue $=440-510 \mathrm{~nm}$, green $=520-590 \mathrm{~nm}$, red $=630-685 \mathrm{~nm}$, red edge $=690-730$, and near-infrared 760-850 nm) (Figure 1). Four RapidEye (Planet, San Francisco, CA, USA) satellite images that included the study site were acquired from the 28 November 2015, 10 December 2015, 20 December 2015, and 20 February 2016. These were the only suitable cloud-free images available during the duration of the experiment. Level 3A RapidEye images were used as an input with a pixel size of $5.0 \mathrm{~m}$. The images were radiometrically and geometrically corrected by the supplier. A noise filter and top-of-atmosphere (TOA) dark object subtraction were applied to each image. The residual geographic error was corrected by manually geo-registering all images to a reference UAV image using a polynomial warping method (ENVI 4.5, 
Harris, Boulder, CO, USA). The total RMS Error after applying the correction across the entire scene was $0.29 \mathrm{~m}$.

\subsection{Image Processing}

Several spectral indices were chosen and calculated from each set of images following a review of the literature on the topic of stress detection using multispectral imagery (Table 2). Spectral indices were selected for inclusion based on the spectral bands available in both datasets and evidence of correlation with plant physiological stress from previous research. The normalised difference vegetation index (NDVI) is a very well known and widely used ratio that has been shown many times to be correlated with plant condition, physiological stress, and photosynthetic activity in a wide range of vegetated environments [55-59]. The green normalised difference vegetation index (GNDVI) and the red edge normalised difference vegetation index (RENDVI) were included specifically to examine the sensitivity of indices including the red edge and green bands from each sensor and to compare these directly to an index based on the red band (NDVI).

Table 2. Spectral indices calculated from the multispectral imagery. This table is modified from [12].

\begin{tabular}{ccc}
\hline Spectral Index & Equation & Source \\
\hline NDVI & $\frac{(N I R-R E D)}{(N I R+R E D)}$ & {$[60]$} \\
GNDVI & $\frac{(N I R-G R E E N)}{N I R+G R E E N}$ & {$[61]$} \\
RENDVI & $\frac{(N I R-R E D E D G E)}{\text { NIR+REDEDGGE }}$ & {$[62,63]$} \\
\hline
\end{tabular}

As data collection spanned several months, methods were required to account for background changes in the target vegetation that were not caused by the experimental treatments. These changes include physiological response to the growing season, changes caused by climatic events, and atmospheric effects that could not be controlled for using other methods [12]. Without a suitable method for control, these influences would confound the physiological stress signal induced by the application of herbicide. Following the method of Healey et al. [64], spectral indices were de-trended to remove the extraneous effects. The approach was based on the assumption that changes in adjacent but untreated parts of the study site could be assumed to be caused by factors unrelated to the herbicide-induced stress. By characterising these unrelated trends we could minimise the potential impact on any signal from the stressed study trees [51].

For the UAV imagery, spectral indices were de-trended by identifying 25 regions of the study area in the final orthomosaic to act as de-trending control areas. A review of the full set of time-series mosaics was carried out to carefully select areas that covered conditions representative of the study plots and the trends in the multi-temporal imagery. The control areas were $5 \mathrm{~m}^{2}$ and were carefully placed to ensure these areas did not overlap the experimental tree clusters. For the RapidEye data, control areas were selected from a nearby $P$. radiata stand with similar growing conditions, terrain, and tree age. Thirty control areas were carefully selected and used to de-trend the RapidEye imagery. For both sets of imagery, the spectral indices extracted from the control areas were deemed to represent the average conditions of the study forest within a specific time step. Spectral indices extracted from both the treated and untreated plots within the experiment were rescaled to the standard deviation above or below the mean forest value for the spectral indices as extracted from the de-trending control areas [64] as follows:

$$
S_{i}=\left(S-S_{\mu}\right) / S_{\delta}
$$

where $S_{i}$ is the rescaled spectral index, $S$ is the original spectral index value, $S_{\mu}$ is the mean value for the control areas within a time step and $S_{\delta}$ is the standard deviation of values from the control 
areas. Using this method, the time-series spectral indices can be de-trended in a robust and easy to implement manner provided that the control areas selected are representative of the average forest conditions within a time step [64].

Raster layers representing the three spectral indices (Table 2) were calculated from each UAV image mosaic and from each satellite image. These were clipped to the boundaries of the study tree canopies that had been carefully delineated using the final image in each time series through digitisation in a GIS (ESRI, Redlands, CA, USA). In the final image, treated trees could be easily and precisely identified. The UAV imagery and the satellite imagery were digitised separately to account for some residual variation caused by differences in sensor geometry. The values for all pixels within the delineated boundaries for treated trees were averaged to provide a mean for each cluster at each acquisition date. For the control (untreated) plots pixels were averaged within the boundary of the original 35 tree plot.

The spectral indices from both datasets were de-trended using the method described earlier [64]. Analysis of the UAV imagery indicated that there was a significant trend in the data that was not due to the herbicide-induced stress [12]. Once the background changes were accounted for, the trend in spectral indices in the treated tree clusters was more pronounced, suggesting that the background noise masking the spectral stress signal had been adequately controlled.

Changes in spectral indices were defined using an approach developed in previous experiments [12,51]. This approach defined a "no-change" zone between the 25th and the 75th percentile of a de-trended spectral index for a given observation at the start of the time-series. Subsequent observations of the same spectral index can be deemed to be stressed if the 75th percentile of the spectral index values for a given observation drops below the lower bound of the "no-change" region defined at the start of the time-series.

To compare the influence of spectral and spatial resolution directly on the detection of physiological stress the UAV imagery was resampled to the same spatial resolution as the RapidEye data $(5 \mathrm{~m})$. A cubic spline resampling was applied to all UAV images using the gdalwarp function of the geospatial data abstraction library (GDAL version 2.2.1) [65] using the standalone version of the GDAL software. The resulting images were manually checked for any visual artefacts associated with the resampling process. All imagery was found to be artefact free and spectral indices were calculated and extracted using the same processing chain applied to the original UAV imagery.

\subsection{Tree Health Data}

The method for field-based, manual tree health monitoring was first described in detail in [12]. Tree canopies of all study trees were assessed for needle discolouration and canopy density from the ground by an experienced assessor who is regularly engaged in forest health monitoring. The assessor undergoes regular training, auditing, and calibration and carries photographic reference material to improve consistency. To reduce the variance associated with assessment subjectivity the same expert assessor was used for all assessments for the duration of the trial. Each tree was assessed from two separate angles, approximately $180^{\circ}$ from each other, so that a comprehensive assessment of the tree canopy could be made. Assessment locations were permanently marked and trees were assessed from these positions at approximately the same time of day at each time. The field assessor followed a commonly used approach to classifying stress symptom expression by scoring percentage canopy discolouration and density into increments of 5 . Wherever possible, ground assessments were made on the same day that UAV data were collected, the longest gap between ground and UAV data collection was three days.

\subsection{Statistical Analysis}

Due to the revisit time of the RapidEye satellites and significant cloud cover in the study area, there were several instances where satellite imagery was not available for days where UAV and ground data had been acquired. As a result, the experimental dataset can be considered as a multivariate time 
series dataset that contains missing values for each observer on certain dates. Analysis of datasets with these characteristics is well studied with considerable research generated from diverse fields such as econometrics [66] and hydrology [67]. Numerous approaches have been developed to estimate the missing time series values to provide a complete dataset for subsequent analysis. All of these methods rely on developing statistical models between variables in the time series data and an ability to model the longitudinal component of the dataset through time. Methods to estimate missing values include multivariate imputation via chained equations [68], regression-based methods [69], and non-parametric, ensemble methods such as Random Forests [70]. Following an examination of several available methods, imputation based on the Random Forest algorithm via the MissForest $\mathrm{R}$ package [71] was selected for use in this study. A complete time series data set was produced with an observation of ground, UAV, and satellite imagery at every acquisition date. This enabled the time series datasets to be plotted through time and a direct exploration of the relationships between all three datasets to be made.

The relationship between UAV and satellite derived spectral indices was explored using regression models. The purpose of the models was to understand the relationship between the two different sensor platforms and to develop predictive models that can be useful for extrapolating information on tree stress derived from the UAV data to larger areas. Ordinary least squares (OLS) was used to produce an initial model. Initial model diagnostic plots were carefully checked for evidence of non-compliance with the assumptions of linear regression analysis and a Durbin-Watson test was used to check for autocorrelation in the model residuals. No evidence of non-compliance was found and so model fitting proceeded using OLS. Univariate models were developed with UAV spectral index as the response and satellite spectral index as the predictor variable. Models up to and including the fifth order polynomial were fitted and the best model for each spectral index was selected based on the Akaike information criterion (AIC) outputted from the R statistical software (version 3.4.2) [72].

Random Forest (RF) regression models [70] were used to examine the capacity of spectral indices extracted from both platforms to detect stress symptoms (canopy discolouration) measured in the field. RF regression utilises ensemble decision tree classifiers, based on bootstrap aggregated sampling (bagging), to construct many individual decision trees, from which a final class assignment is determined [70]. RF has previously been used to successfully model several plantation forest variables using remotely sensed data $[6,7,73,74]$. The RF algorithm constructs decision trees using a bootstrap sample from the available training data, with the remaining data assigned as out-of-bag (OOB) samples. At each node, a random subset of predictor variables is tested to partition the observation data into increasingly homogeneous subsets. The node-splitting variable selected from the variable subset is that which resulted in the greatest increase in data purity (variance or Gini) before and after the tree node split [75]. The OOB sample data are used to compute accuracies and error rates averaged over all predictions, and estimate variable importance [75,76]. RF provides methods to estimate the importance of each predictor variable in the model. The mean decrease in accuracy (MDA) importance measure is calculated as the normalised difference between OOB accuracy of the original observations to randomly permuted variables [75-77]. RF is a well-regarded machine learning tool that has the capacity to identify complex and non-linear relationships in the fitting dataset and offers high classification accuracy $[75,77,78]$.

RF models were fitted using the randomForest $R$ package [79], the initial model included all three spectral indices from both platforms and aggregated all data from the entire time-series dataset. The model performance and the relative importance of the predictors were used to provide insight into the sensitivity of the spectral indices to physiological stress. In a subsequent iterative processing step, RF models were fitted using only UAV predictors and only satellite-derived predictors to assess the relative utility of these data. The mean square error calculated from model out-of-bag errors and the coefficient of determination $\left(\mathrm{R}^{2}\right)$ were used to assess model precision. Conditional random forest variable importance calculated using the party $\mathrm{R}$ package [80-82] were used to provide insight into the predictive power of metrics from data from both sources. Conditional importance scores were 
used as the variable importance scores calculated from RF have been shown to be biased in some situations [81].

\section{Results}

\subsection{Data Summary}

In total, 25 separate datasets were collected, processed, and available for inclusion in this analysis. In most cases, the field data and the UAV multispectral imagery were recorded on the same date. All UAV imagery from the 27 November was abandoned as unfavourable weather conditions made the data unusable. After March 2016, the study trees were harvested and the study was concluded as no further data could be collected. For a summary of the tree health data assessed from the ground, readers should refer to Dash et al. [12].

\subsection{Spectral Indices}

The spectral indices extracted from the control plots stayed within the 'no-change' region for both remote sensing data sources throughout the duration of the experiment (Figure 2). By contrast, within the treated plots, spectral indices derived from both platforms exhibited a significant decline over time. Indices derived from satellite imagery showed a marked reduction 75 days after treatment that was well below the "no-change" region for NDVI and RENDVI and marginally below this region for GNDVI. For UAV data all indices dropped below the no-change region 29 days after treatment. This decline continued throughout the duration of the experiment for NDVI but levelled out 52 days after treatment for the other two indices (Figure 2).

Analysing the changes in spectral indices within the canopies of tree clusters of different sizes provides insight into the sensitivity of each sensor to physiological stress expression at different spatial scales. Spectral indices derived from the UAV sensor showed the most marked changes over time in NDVI. For all treatment cluster sizes, there was a marked decline in NDVI that moved below the no-change region 29 days after treatment and continued to decline until the end of the experiment (Figure 3). Values of GNDVI and RENDVI dropped below the no-change region at day 29. However, after an initial decline, values of these indices stabilised after day 53 for most cluster sizes and exhibited a sharp increase for the single tree clusters 64 days after treatment. The magnitude of reductions in all indices scaled positively with cluster size. By day 87, reductions in GNDVI, NDVI, and RENDVI were respectively, $0.89,8.66$, and 2.41 for single tree clusters and 3.18, 11.93, and 5.28 for clusters with 16 trees. Spectral indices derived from the satellite imagery were not sufficiently sensitive to detect treatment changes in smaller clusters of trees. All indices remained within the 'no-change' zone until 13 days after treatment. For cluster sizes of four or more trees, values for all indices were below the 'no-change' zone for the next imagery acquisition 75 days after treatment. In contrast, index values for clusters of two or fewer trees showed very little change 75 days after treatment. For these smaller clusters, there was only marginal movement below the 'no-change' zone for RENDVI in single tree clusters (Figure 3). All indices showed greater reductions as cluster size increased and changes were very muted for the two smallest clusters. Reductions in GNDVI, NDVI, and RENDVI 75 days after treatment ranged from $0.29,0.38$, and 0.53 for single tree clusters to 2.01, 5.84, and 5.40 for clusters with 16 trees. For both sensors and for all indices no decline below the 'no-change' zone was observed for the control plots where no herbicide was applied.

\subsection{Spatial Resolution}

Through resampling the UAV imagery to the spatial resolution of the RapidEye data we examined the influence of spatial resolution on sensitivity to physiological stress onset. The general trends in the spectral indices were very similar between the original UAV imagery and the imagery that was resampled to $5 \mathrm{~m}$ (Figure 4). Restricting the analyses to data from 64 and 87 days after treatment (as this spanned the time of the satellite imagery acquisition) the mean reduction in NDVI and 
RENDVI was greater in the resampled imagery than the original imagery for clusters with sixteen (NDVI 14.6 vs. 11.9; RENDVI 6.39 vs. 5.28) and eight trees (NDVI 13.0 vs. 12.2; RENDVI 5.05 vs. 4.81 ). In contrast, there was a smaller shift in these indices for resampled imagery with clusters of four (NDVI 9.55 vs. 9.87 ; RENDVI 3.80 vs. 4.03 ), two (NDVI 8.18 vs. 9.63; RENDVI 3.18 vs. 3.86 ), and single trees (NDVI 5.32 vs. 8.66; RENDVI 1.25 vs. 2.41). Similar patterns were observed for the less sensitive metric GNDVI. Compared to the original imagery, the resampled imagery showed greater shifts in GNDVI for clusters of eight or more trees and smaller shifts in GNDVI for clusters with four or fewer trees.

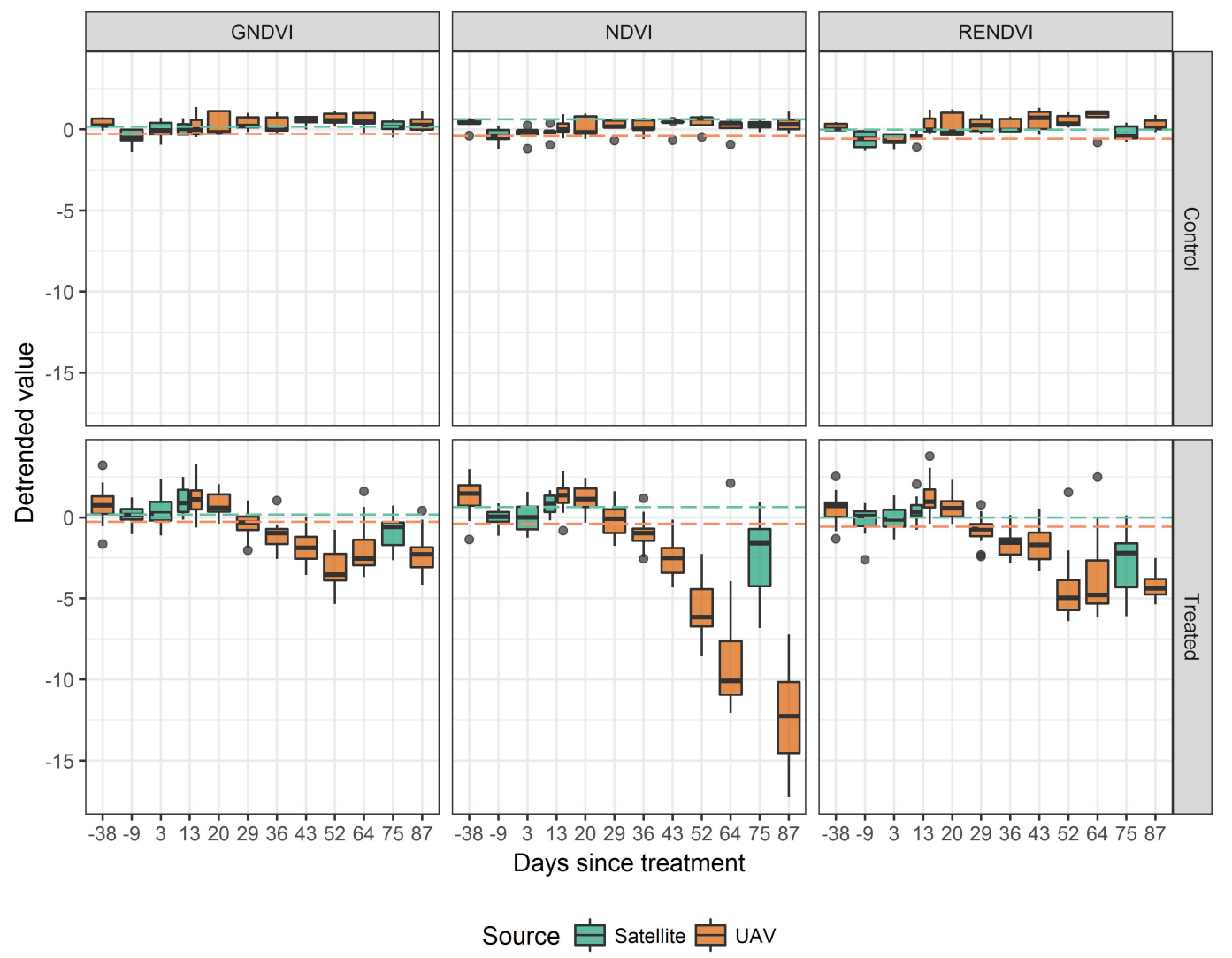

Figure 2. Box and whisker plots showing the distribution of three de-trended spectral indices derived from the two different sensors for control $(n=5)$ and treated $(n=25)$ plots over the course of the experiment.The dashed lines show the lower bound of the 'no-change' zone calculated from both treated and control plots during the first time step. Change is deemed to have occurred once the upper hinge of the box plot is below the 'no-change' bound.

If the differences in the spectral indices observed between the satellite and UAV sensors were solely the result of spatial resolution then we would expect to see very similar results extracted from the satellite data and the resampled UAV imagery. In contrast to this expectation, resampling increased the magnitude of these differences for the larger cluster sizes with eight and sixteen trees, as described above. Consequently, the resampling process resulted in greater differences in all indices between data derived from UAV and satellite sensors for these two cluster sizes. Although resampling the UAV data decreased the magnitude of reductions in indices derived from smaller cluster sizes these values were still substantially larger than those derived from satellite imagery for cluster sizes of four trees (NDVI 9.55 vs. 2.12; RENDVI 3.80 vs. 2.57; GNDVI 2.30 vs. 0.56), two trees (NDVI 8.18 vs. 0.16; RENDVI 3.18 vs. 1.82 ; GNDVI 0.9 vs. 0.14 ), and single trees (NDVI 5.32 vs. 0.38 ; RENDVI 1.25 vs. 0.53; GNDVI 0.39 vs. 0.29 ). 


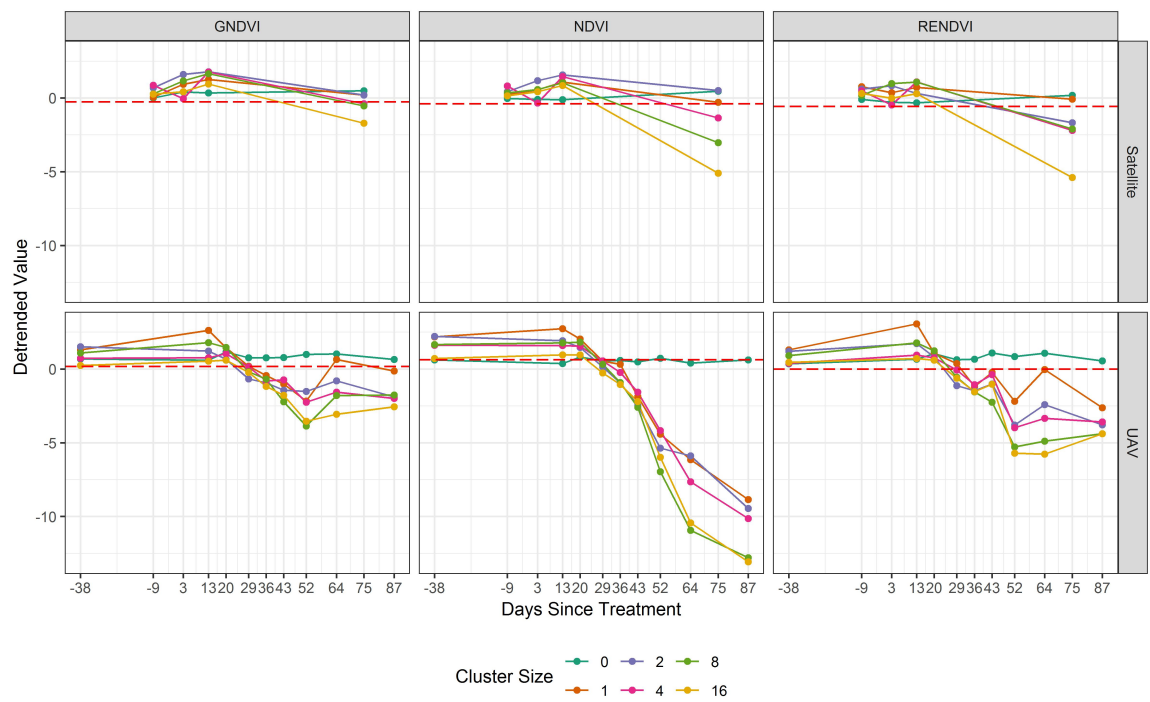

Figure 3. Each datum represents the 75th percentile of the spectral indices for an experimental cluster size for both sensors across the duration of the study. The control plots where no trees were treated are represented by the cluster size $=0$. The red dashed line shows the 25 th percentile of the pre-treatment values and defines the lower bound of the 'no-change' region for a spectral index. The UAV results plotted here have been previously displayed in [12].

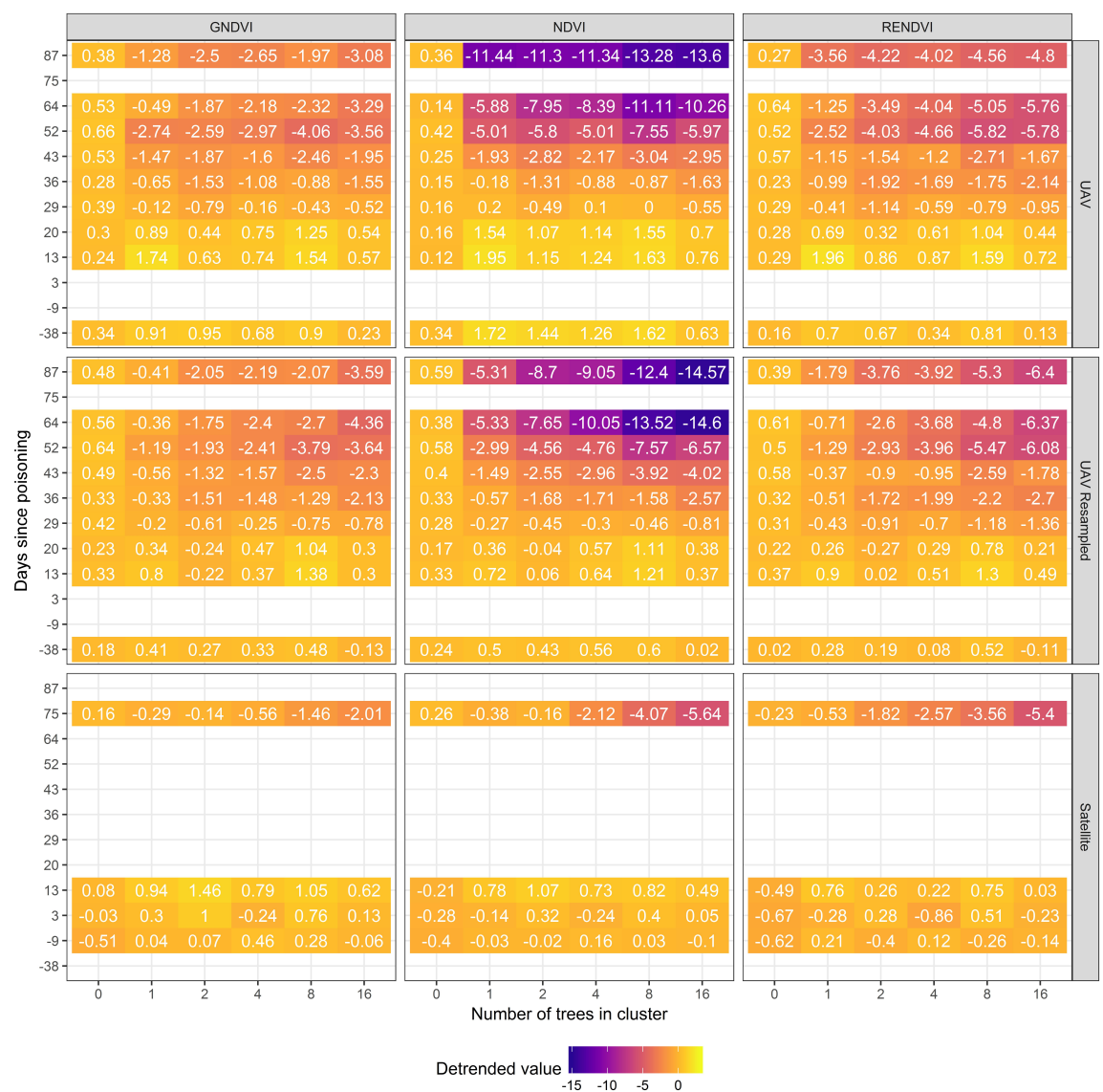

Figure 4. Each tile displays the mean de-trended spectral indices calculated from a given cluster size from a specific image source on a specific day. UAV-Resampled imagery shows the results extracted from UAV imagery resampled to the spatial resolution of the RapidEye data. 


\subsection{Comparing $U A V$ and Satellite Imagery}

Changes in de-trended vegetation indices were compared following imputation of missing values in the experimental dataset (Figure 5). The values extracted from the UAV and satellite imagery were very similar up to 20 days following treatment for all three spectral indices examined. Although indices followed a similar general trend after this point, reductions in indices were greater for the data from the UAV than the satellite sensor. This divergence in indices was most pronounced for NDVI.

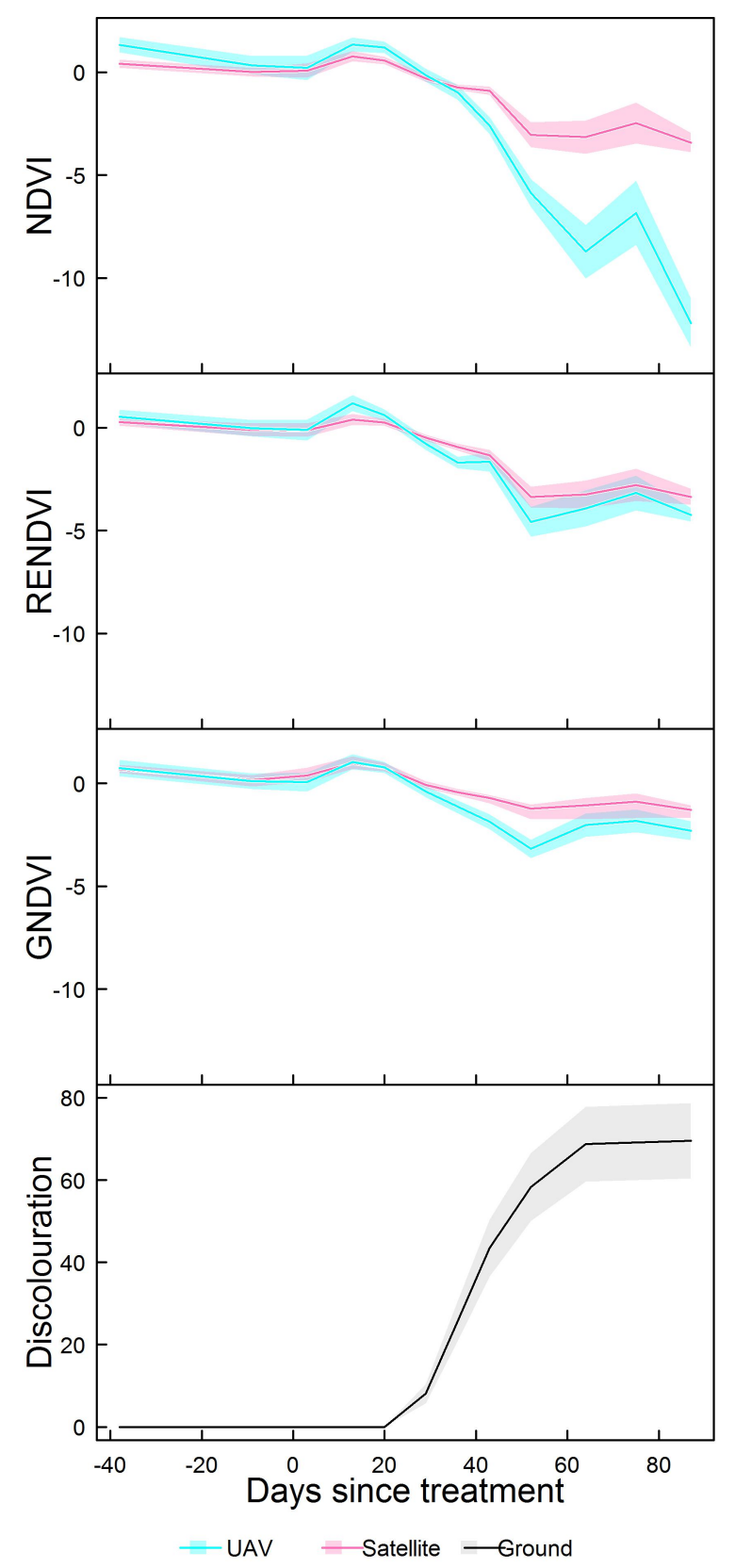

Figure 5. The change in the de-trended vegetation indices and field measured discolouration plotted against days after treatment. The solid line shows the mean at each time step and the shaded area shows the confidence interval. For each spectral index the values relate to the mean value of pixels within a cluster. For the ground measured discolouration the values represent observations of the field technician. 
The relationship between satellite and UAV sensors was investigated using the imputed dataset (Figure 6) where missing observations had been imputed using missForest. For both NDVI and GNDVI, linear models described the relationship most accurately. For RENDVI the best model was a second order polynomial. All developed models had high precision and model strength was greatest for RENDVI $\left(R^{2}=0.92\right)$ followed by GNDVI $\left(R^{2}=0.84\right)$, and then NDVI $\left(R^{2}=0.82\right)$.
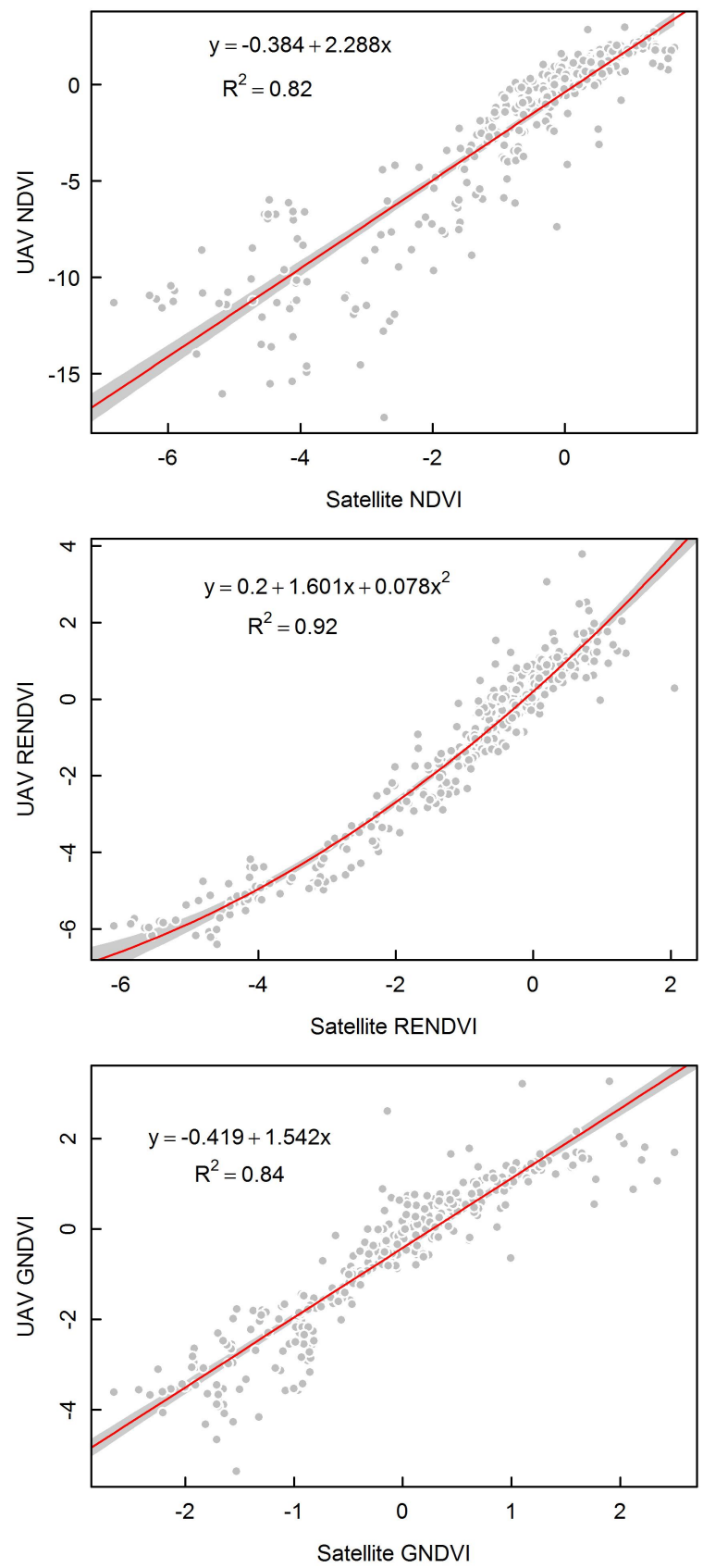

Figure 6. The relationship between UAV and satellite-derived vegetation indices. Each datum represents the mean results extracted from a single time step for a tree cluster and the shaded area shows the confidence interval.

A RF regression model was used to investigate the ability of both data sources to predict field measured discolouration as reflected by visible discolouration. A single RF model (RMSE $=15.1$, bias $=-0.02$ ) was used to examine the relationship and this was able to account for $82.3 \%$ of the 
variability in the response. The conditional importance scores revealed that the NDVI index collected from the UAV imagery was the most important variable for predicting discolouration (Figure 7). The second most important predictor was the satellite RENDVI index, while the subsequent metrics from both sensors were less important. RF regression models were also fitted using subsets of predictors from only one data source to compare with the initial model fitted with all predictors. The model using only UAV data was found to be more precise than the model that used spectral indices from the satellite data $\left(R^{2}=0.84, \operatorname{RMSE}=15.04\right.$, bias $=0.13$ vs. $R^{2}=0.73, \operatorname{RMSE}=18.56$, bias $\left.=-0.03\right)$.

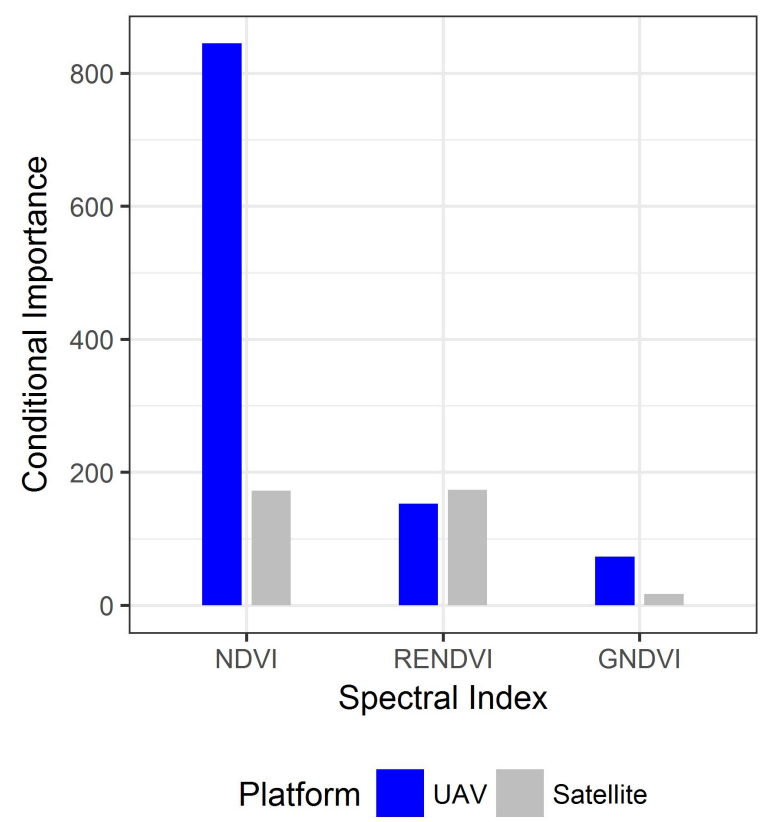

Figure 7. Conditional importance scores for all variables in the RF regression model.

\section{Discussion}

Spectral indices calculated from multispectral imagery were sufficiently robust to detect the onset of physiological stress within this experiment. Conifer foliage may be damaged and change colour due to a variety of agents, such as insects, root rot, fungi, and drought [83]. Independent of the causal agent, under physiological stress foliar moisture declines, chlorophyll and other pigment molecules break down, and this is followed by a break down of intra-cellular and cellular structures $[63,83]$. Hyperspectral imagery has been most often used to detect natural variation in pigments [84,85] and elemental concentrations [86] although recent research suggests that precise models can be developed for chlorophyll concentration within tree canopies from multispectral imagery [87]. Detection of the more pronounced changes in needle chemistry and appearance associated with needle mortality can be robustly predicted using multispectral imagery [19,88-92] which is consistent with our findings.

Results from this study, and previous analyses [12], showed NDVI and RENDVI to be the most sensitive indicators of the onset of physiological stress. High values of NDVI in healthy foliage occur due to the contrast of low leaf reflectance in the red band and higher reflectance within the near-infrared band. As the foliage senesces, chlorophyll declines to cause an increase in red band reflectance resulting in reductions in NDVI [46]. NDVI is one of the most widely-used spectral indices developed over the last 40 years [93] and has been widely used to discriminate healthy from stressed foliage within forests [94-98]. A large body of research has also demonstrated that increased reflectance in stressed vegetation relative to healthy vegetation is also strongly evident along the red edge (680-750 nm) region $[61,88]$ and many studies have shown the red edge to be a more sensitive indicator of the onset of stress than either the green or red bands [51]. Consequently, indices based on the red edge band have 
also been widely used to detect stress [51] and defoliation resulting from insect attack and drought in conifers $[19,89,90,92]$.

Differences in the relative importance of indices were observed between platforms in our study. NDVI derived from the UAV data was the most important predictor of field measured discolouration while RENDVI was the strongest predictor of discolouration for the satellite data. These variations may reflect the different spectral ranges covered by the two sensors examined. The greater importance of RENDVI for the satellite data may be attributable to broader coverage of the red edge from this platform (690-730 nm), compared to the red edge region covered by the UAV mounted sensor which is limited to a narrower spectral window $(707-727 \mathrm{~nm})$. Previous studies have indicated that across a range of higher plants the optimum wavelength for early detection of stress was $700 \mathrm{~nm}$ [99]. However, an investigation of the stress detection in the conifer Balsam fir (Abies balsamea (L.) Mill) indicated that reflectance at $711 \mathrm{~nm}$ was the most responsive [100]. These studies indicate that there may be some variance in the precise wavelength where stress is most evident. As the RapidEye sensor covers the entirety of the red edge region for the typical spectral response of plants it is likely to be highly sensitive to changes in this region. The considerably narrower bands of the multispectral sensor could result in a failure to detect very early spectral changes associated with physiological stress. Furthermore, it should be noted that the incomplete time series provided by both sensors means that the sensitivity of both platforms to the earliest signs of physiological stress could be confounded.

Although sensors on both platforms were sensitive to the symptoms of physiological stress, changes in NDVI associated with stress were more pronounced using UAV data. By restricting analysis to clusters larger than the pixel size of satellite imagery (4-16 trees) and to data from 64-87 days after treatment the mean reduction across treated groups for imagery from the UAV, resampled UAV imagery, and satellite imagery averaged $-11.33,-12.67$, and -3.94 , respectively, for NDVI and -4.71 , $-5.08,-3.84$, respectively, for RENDVI. This result suggests that the lower sensitivity of the satellite imagery was not solely attributable to differences in spatial resolution. Substantial differences remained between the UAV and satellite data after the UAV data were resampled to the same spatial resolution. Resampling minimised the effect of spatial resolution on sensitivity but the effects of differences caused by atmospheric conditions and sensor spectral properties remained. It is logical to conclude that the greater sensitivity of the UAV data to minor changes is attributable to the narrower bandwidths of the UAV sensor compared to the RapidEye sensor and the proximity of the UAV platform to the subject trees. However, the increase in the sensitivity of resampled spectral indices may be a product of the resampling process and should not be interpreted as direct evidence that coarser spatial resolution imagery has greater utility for stress monitoring. Alternatively, this could be the result of a greater signal-to-noise ratio in coarser resolution imagery when the subject phenomenon is equal to or larger than the pixel size of the imagery used. Further research should be undertaken to more precisely partition the influences of spectral and spatial resolution on detection of stress so that the limits of multispectral imagery can be more robustly defined.

Imagery acquired from a UAV was sensitive to stress in tree clusters of all sizes. It was interesting to note that changes in NDVI were of a similar magnitude for cluster sizes greater than $25 \mathrm{~m}^{2}$ when the imagery was resampled to a $5 \mathrm{~m}$ resolution. This finding is consistent with previous research that demonstrated the utility of moderate resolution multispectral imagery for detection of stress. Studies that have used multispectral imagery to detect insect damage suggest the optimal resolution to be $2.4 \mathrm{~m}$ [48] for Pinus contorta dominated stands, 1.25-2.25 m for Eucalyptus spp. [98] and 1.75-2.3 m for $P$. radiata [101]. However, the magnitude of the change in spectral indices for smaller clusters and individual trees was lower for the resampled imagery.

Our findings clearly show that spectral indices derived from satellite imagery were only useful for detecting stress in clusters of four or more trees. Satellite imagery has been successfully used to detect major outbreaks of devastating insect damage that result in tree mortality. For example, recent studies, that investigate mortality from outbreaks of mountain pine beetle Dendroctonus ponderosae (Hopkins), showed classification accuracies ranging from 67-78\% for medium resolution [91,102,103] 
to accuracies of $71-93 \%$ when high-resolution satellite imagery was used $[20,21,90,104]$. However, no research has examined the precision of satellite imagery in detecting different sized clusters of stressed or diseased trees under controlled conditions. Our results demonstrate the sensitivity of satellite imagery for detecting stress symptoms and define the detection limits of stress in mature P. radiata for this sensor type.

The success of forest surveillance is largely governed by being able to match the temporal, spatial, and spectral characteristics of symptoms with an appropriate platform, sensor, and analytical method. Results from this study demonstrate the complementary role that UAV and satellite platforms could play in the detection of stress as symptoms develop. Solutions that can automate disease detection from fine to medium resolution satellite imagery could be used to identify the location of potential outbreaks. Once an outbreak has been detected, fine-scale imagery could be collected from UAVs to regularly monitor an infection front across an area of interest in a cost-effective way. Data collection from UAVs is considerably cheaper and can be collected in a greater range of weather conditions than satellite data. Our research shows that the multispectral sensors studied are compatible and can be used in a complementary manner. As a result, the UAV data can be used to augment the data collected from the satellite platforms and enhance our understanding of the spatial distribution of disease expression across forest ecosystems.

Our findings also show that data from the RapidEye satellite can be used to expand the range of physiological stress monitoring that can be achieved using a UAV sensor. However, the RapidEye sensor offers lower sensitivity as it was only suitable for detecting stress in larger clusters. When used in combination these two technologies offer a solution for both widespread and fine-grained monitoring of plantation forests. This system can be deployed to track physiological stress and to put in place management activities to mitigate stress and increase forest productivity.

The knowledge developed through this experiment can be useful for the designers of multi-scale detection systems for tracking biosecurity incursions. Intensive, high-resolution UAV surveys could be deployed over high-risk sites and larger, less sensitive, satellite methods could be used across wider areas. In combination, an approach of this type could provide an extremely practical tool as both an early warning system and in monitoring the spread of an incursion.

\section{Conclusions}

Our research clearly shows that both UAV and satellite imagery have significant capability to detect plant stress in mature $P$. radiata trees under controlled experimental conditions. This is evidenced by the deviation of spectral indices from both sensors from the "no-change" region and from close correlations with the field observations of tree health. This result suggests that a more comprehensive monitoring platform can be developed by combining both sensor technologies. This would aid precision forest management by enabling both coarse, broad-scale monitoring of disease progression and fine-scale changes that might indicate new or early disease outbreaks. We found that smaller scale instances of herbicide induced stress require finer spatial resolution imagery for detection. This supports our hypothesis that the higher resolution UAV imagery provides greater sensitivity to physiological stress than coarser satellite imagery. We have also defined the lower spatial bound for physiological stress detection for the RapidEye satellite. In our experiment, the lower spatial bound for stress detection was found to be the area represented by 4 or more trees, this equated to an area of approximately $77 \mathrm{~m}^{2}$ on average. This finding suggests that, using this approach and the indices examined, the RapidEye sensor is sensitive to changes at a spatial resolution that is approximately twice the pixel size of the derived imagery. This may be useful for managers engaged in planning and acquisition of satellite imagery. Our experiment showed that the UAV and satellite imagery data used are complementary and can be used in combination to provide a more complete means of detecting and monitoring physiological stress patterns in forested ecosystems. This multi-sensor approach will lead to the augmentation and enhancement of current approaches based on a single platform. 
Author Contributions: Conceptualization, J.P.D. and M.S.W.; Data Curation, J.P.D.; Formal Analysis, J.P.D. and G.D.P.; Investigation, J.P.D., G.D.P. and M.S.W.; Methodology, J.P.D.; Visualization, J.P.D.; Writing-Original Draft, J.P.D.; Writing—Review \& Editing, G.D.P. and M.S.W.

Funding: This study was funded as part of the Growing Confidence in Forestry's Future (GCFF) programme (Contract number: CO4X1306). GCFF was co-funded by the Forest Growers Levy Trust and the New Zealand Ministry of Business, Innovation and Employment (MBIE).

Acknowledgments: The authors recognise the contributions of Toby Stovold, Kane Fleet, Marie Heaphy, Mark Miller and Rod Brownlie who completed all field work and Heidi Dungey who helped develop the study methods. Scion colleague Stefan Gous is acknowledged for offering advice on herbicide application rates. We are grateful to the forest managers for providing access and allowing us to complete this study in their forest.

Conflicts of Interest: The authors declare no conflict of interest.

\section{References}

1. Moore, J.R.; Dash, J.P.; Lee, J.R.; McKinley, R.B.; Dungey, H.S. Quantifying the influence of seedlot and stand density on growth, wood properties and the economics of growing radiata pine. Forestry 2017, 91, 327-340, doi:10.1093/forestry/cpx016. [CrossRef]

2. Watt, M.S.; Kimberley, M.O.; Dash, J.P.; Harrison, D. Spatial prediction of optimal final stand density for even-aged plantation forests using productivity indices. Can. J. For. Res. 2017, 47, 527-535, doi:10.1139/cjfr-2016-0220. [CrossRef]

3. Klapste, J.; Suontama, M.; Telfer, E.; Graham, N.; Low, C.; Stovold, T.; McKinley, R.; Dungey, H. Exploration of genetic architecture through sib-ship reconstruction in advanced breeding population of Eucalyptus nitens. PLoS ONE 2017, 12, e0185137, doi:10.1371/journal.pone.0185137. [CrossRef] [PubMed]

4. Li, Y.; Xue, J.; Clinton, P.W.; Dungey, H.S. Genetic parameters and clone by environment interactions for growth and foliar nutrient concentrations in radiata pine on 14 widely diverse New Zealand sites. Tree Genet. Genomes 2015, 11, 10, doi:10.1007/s11295-014-0830-1. [CrossRef]

5. Maggard, A.O.; Will, R.E.; Wilson, D.S.; Meek, C.R.; Vogel, J.G. Fertilization can compensate for decreased water availability by increasing the efficiency of stem volume production per unit of leaf area for loblolly pine (Pinus taeda) stands. Can. J. For. Res. 2017, 47, 445-457, doi:10.1139/cjfr-2016-0422. [CrossRef]

6. Watt, M.S.; Dash, J.P.; Bhandari, S.; Watt, P. Comparing parametric and non-parametric methods of predicting Site Index for radiata pine using combinations of data derived from environmental surfaces, satellite imagery and airborne laser scanning. For. Ecol. Manag. 2015, 357, 1-9, doi:10.1016/j.foreco.2015.08.001. [CrossRef]

7. Watt, M.S.; Dash, J.P.; Watt, P.; Bhandari, S. Multi-sensor modelling of a forest productivity index for radiata pine plantations. N. Z. J. For. Sci. 2016, 46, 9, doi:10.1186/s40490-016-0065-z. [CrossRef]

8. Pearse, G.D.; Morgenroth, J.; Watt, M.S.; Dash, J.P. Optimising prediction of forest leaf area index from discrete airborne lidar. Remote Sens. Environ. 2017, 200, 220-239, doi:10.1016/j.rse.2017.08.002. [CrossRef]

9. Paoletti, E. Impact of ozone on Mediterranean forests: A review. Environ. Pollut. 2006, 144, 463-474, doi:10.1016/j.envpol.2005.12.051. [CrossRef] [PubMed]

10. Marco, A.D.; Vitale, M.; Popa, I.; Anav, A.; Badea, O.; Silaghi, D.; Leca, S.; Screpanti, A.; Paoletti, E. Ozone exposure affects tree defoliation in a continental climate. Sci. Total Environ. 2017, 596-597, 396-404, doi:10.1016/j.scitotenv.2017.03.135. [CrossRef] [PubMed]

11. Moore, J.R.; Watt, M.S. Modelling the influence of predicted future climate change on the risk of wind damage within New Zealand's planted forests. Glob. Chang. Biol. 2015, 21, 3021-3035, doi:10.1111/gcb.12900. [CrossRef] [PubMed]

12. Dash, J.P.; Watt, M.S.; Pearse, G.D.; Heaphy, M.; Dungey, H.S. Assessing very high resolution UAV imagery for monitoring forest health during a simulated disease outbreak. ISPRS J. Photogramm. Remote Sens. 2017, 131, 1-14, doi:10.1016/j.isprsjprs.2017.07.007. [CrossRef]

13. Bulman, L.S.; Bradshaw, R.E.; Fraser, S.; Martín-García, J.; Barnes, I.; Musolin, D.L.; La Porta, N.; Woods, A.J.; Diez, J.J.; Koltay, A.; et al. A worldwide perspective on the management and control of Dothistroma needle blight. For. Pathol. 2016, 46, 472-488, doi:10.1111/efp.12305. [CrossRef]

14. Coops, N.; Stanford, M.; Old, K.; Dudzinski, M.; Culvenor, D.; Stone, C. Assessment of Dothistroma Needle Blight of Pinus radiata Using Airborne Hyperspectral Imagery. Phytopathology 2003, 93, 1524-1532, doi:10.1094/PHYTO.2003.93.12.1524. [CrossRef] [PubMed] 
15. Meigs, G.W.; Kennedy, R.E.; Cohen, W.B. A Landsat time series approach to characterize bark beetle and defoliator impacts on tree mortality and surface fuels in conifer forests. Remote Sens. Environ. 2011, 115, 3707-3718, doi:10.1016/j.rse.2011.09.009. [CrossRef]

16. Eklundh, L.; Johansson, T.; Solberg, S. Mapping insect defoliation in Scots pine with MODIS time-series data. Remote Sens. Environ. 2009, 113, 1566-1573, doi:10.1016/j.rse.2009.03.008. [CrossRef]

17. Fraser, R.; Latifovic, R. Mapping insect-induced tree defoliation and mortality using coarse spatial resolution satellite imagery. Int. J. Remote Sens. 2005, 26, 193-200, doi:10.1080/01431160410001716923. [CrossRef]

18. Pasquarella, V.J.; Bradley, B.A.; Woodcock, C.E. Near-Real-Time Monitoring of Insect Defoliation Using Landsat Time Series. Forests 2017, 8, doi:10.3390/f8080275. [CrossRef]

19. Stone, C.; Penman, T.; Turner, R. Managing drought-induced mortality in Pinus radiata plantations under climate change conditions: A local approach using digital camera data. For. Ecol. Manag. 2012, 265, 94-101, doi:10.1016/j.foreco.2011.10.008. [CrossRef]

20. Coops, N.C.; Johnson, M.; Wulder, M.A.; White, J.C. Assessment of QuickBird high spatial resolution imagery to detect red attack damage due to mountain pine beetle infestation. Remote Sens. Environ. 2006, 103, 67-80, doi:10.1016/j.rse.2006.03.012. [CrossRef]

21. Hicke, J.A.; Logan, J. Mapping whitebark pine mortality caused by a mountain pine beetle outbreak with high spatial resolution satellite imagery. Int. J. Remote Sens. 2009, 30, 4427-4441, doi:10.1080/01431160802566439. [CrossRef]

22. Poona, N.K.; Ismail, R. Discriminating the occurrence of pitch canker fungus in Pinus radiata trees using QuickBird imagery and artificial neural networks. South. For. 2013, 75, 29-40, doi:10.2989/20702620.2012.748255. [CrossRef]

23. Abdel-Rahman, E.M.; Mutanga, O.; Adam, E.; Ismail, R. Detecting Sirex noctilio grey-attacked and lightning-struck pine trees using airborne hyperspectral data, random forest and support vector machines classifiers. ISPRS J. Photogramm. Remote Sens. 2014, 88, 48-59, doi:10.1016/j.isprsjprs.2013.11.013. [CrossRef]

24. Dash, J.P.; Pont, D.; Brownlie, R.K.; Dunningham, A.; Watt, M.S.; Pearse, G.D. Remote sensing for precision forestry. N. Z. J. For. 2016, 64, 12.

25. Puliti, S.; Ene, L.T.; Gobakken, T.; Næsset, E. Use of partial-coverage UAV data in sampling for large scale forest inventories. Remote Sens. Environ. 2017, 194, 115-126, doi:10.1016/j.rse.2017.03.019. [CrossRef]

26. Miller, E.; Dandois, J.P.; Detto, M.; Hall, J.S. Drones as a Tool for Monoculture Plantation Assessment in the Steepland Tropics. Forests 2017, 8, doi:10.3390/f8050168. [CrossRef]

27. Goodbody, T.R.; Coops, N.C.; Marshall, P.L.; Tompalski, P.; Crawford, P. Unmanned aerial systems for precision forest inventory purposes: A review and case study. For. Chron. 2017, 93, 71-81, doi:10.5558/tfc2017-012. [CrossRef]

28. Kachamba, D.J.; Ørka, H.O.; Gobakken, T.; Eid, T.; Mwase, W. Biomass Estimation Using 3D Data from Unmanned Aerial Vehicle Imagery in a Tropical Woodland. Remote Sens. 2016, 8, 968, doi:10.3390/rs8110968. [CrossRef]

29. Wallace, L.; Lucieer, A.; Malenovský, Z.; Turner, D.; Vopěnka, P. Assessment of Forest Structure Using Two UAV Techniques: A Comparison of Airborne Laser Scanning and Structure from Motion (SfM) Point Clouds. Forests 2016, 7, doi:10.3390/f7030062. [CrossRef]

30. Messinger, M.; Asner, G.P.; Silman, M. Rapid Assessments of Amazon Forest Structure and Biomass Using Small Unmanned Aerial Systems. Remote Sens. 2016, 8, 615, doi:10.3390/rs8080615. [CrossRef]

31. Goodbody, T.R.H.; Coops, N.C.; Tompalski, P.; Crawford, P.; Day, K.J.K. Updating residual stem volume estimates using ALS- and UAV-acquired stereo-photogrammetric point clouds. Int. J. Remote Sens. 2017, 38, 2938-2953, doi:10.1080/01431161.2016.1219425. [CrossRef]

32. Watt, M.S.; Heaphy, M.; Dunningham, A.; Rolando, C. Use of remotely sensed data to characterize weed competition in forest plantations. Int. J. Remote Sens. 2017, 38, 2448-2463, doi:10.1080/01431161.2016.1230290. [CrossRef]

33. Cardil, A.; Vepakomma, U.; Brotons, L. Assessing Pine Processionary Moth Defoliation Using Unmanned Aerial Systems. Forests 2017, 8, doi:10.3390/f8100402. [CrossRef]

34. Näsi, R.; Honkavaara, E.; Lyytikäinen-Saarenmaa, P.; Blomqvist, M.; Litkey, P.; Hakala, T.; Viljanen, N.; Kantola, T.; Tanhuanpää, T.; Holopainen, M. Using UAV-Based Photogrammetry and Hyperspectral Imaging for Mapping Bark Beetle Damage at Tree-Level. Remote Sens. 2015, 7, 15467-15493, doi:10.3390/rs71115467. [CrossRef] 
35. Michez, A.; Piégay, H.; Lisein, J.; Claessens, H.; Lejeune, P. Classification of riparian forest species and health condition using multi-temporal and hyperspatial imagery from unmanned aerial system. Environ. Monit. Assess. 2016, 188, 146, doi:10.1007/s10661-015-4996-2. [CrossRef] [PubMed]

36. Cruz, H.; Eckert, M.; Meneses, J.; Martínez, J.F. Efficient Forest Fire Detection Index for Application in Unmanned Aerial Systems (UASs). Sensors 2016, 16, 893, doi:10.3390/s16060893. [CrossRef] [PubMed]

37. Yuan, C.; Liu, Z.; Zhang, Y. Aerial Images-Based Forest Fire Detection for Firefighting Using Optical Remote Sensing Techniques and Unmanned Aerial Vehicles. J. Intell. Robot. Syst. 2017, 88, 635-654, doi:10.1007/s10846-016-0464-7. [CrossRef]

38. Mokroš, M.; Výbošt'ok, J.; Merganič, J.; Hollaus, M.; Barton, I.; Koreň, M.; Tomaštík, J.; Čerňava, J. Early Stage Forest Windthrow Estimation Based on Unmanned Aircraft System Imagery. Forests 2017, 8, doi:10.3390/f8090306. [CrossRef]

39. Samiappan, S.; Turnage, G.; McCraine, C.; Skidmore, J.; Hathcock, L.; Moorhead, R. Post-Logging Estimation of Loblolly Pine (Pinus taeda) Stump Size, Area and Population Using Imagery from a Small Unmanned Aerial System. Drones 2017, 1, doi:10.3390/drones1010004. [CrossRef]

40. Fraser, R.H.; van der Sluijs, J.; Hall, R.J. Calibrating Satellite-Based Indices of Burn Severity from UAV-Derived Metrics of a Burned Boreal Forest in NWT, Canada. Remote Sens. 2017, 9, 279, doi:10.3390/rs9030279. [CrossRef]

41. Stark, D.J.; Vaughan, I.P.; Evans, L.J.; Kler, H.; Goossens, B. Combining drones and satellite tracking as an effective tool for informing policy change in riparian habitats: A proboscis monkey case study. Remote Sens. Ecol. Conserv. 2018, 4, 44-52, doi:10.1002/rse2.51. [CrossRef]

42. Szantoi, Z.; Smith, S.E.; Strona, G.; Koh, L.P.; Wich, S.A. Mapping orangutan habitat and agricultural areas using Landsat OLI imagery augmented with unmanned aircraft system aerial photography. Int. J. Remote Sens. 2017, 38, 2231-2245, doi:10.1080/01431161.2017.1280638. [CrossRef]

43. Marx, A.; McFarlane, D.; Alzahrani, A. UAV data for multi-temporal Landsat analysis of historic reforestation: A case study in Costa Rica. Int. J. Remote Sens. 2017, 38, 2331-2348, doi:10.1080/01431161.2017.1280637. [CrossRef]

44. Puliti, S.; Saarela, S.; Gobakken, T.; Ståhl, G.; Næsset, E. Combining UAV and Sentinel-2 auxiliary data for forest growing stock volume estimation through hierarchical model-based inference. Remote Sens. Environ. 2018, 204, 485-497, doi:10.1016/j.rse.2017.10.007. [CrossRef]

45. Abdollahnejad, A.; Panagiotidis, D.; Surový, P. Estimation and Extrapolation of Tree Parameters Using Spectral Correlation between UAV and Pléiades Data. Forests 2018, 9, 85, doi:10.3390/f9020085. [CrossRef]

46. Rullan-Silva, C.; Olthoff, A.; de la Mata, J.D.; Pajares-Alonso, J. Remote monitoring of forest insect defoliation-A Review. For. Syst. 2013, 22, 377-391. [CrossRef]

47. Garrity, S.R.; Allen, C.D.; Brumby, S.P.; Gangodagamage, C.; McDowell, N.G.; Cai, D.M. Quantifying tree mortality in a mixed species woodland using multitemporal high spatial resolution satellite imagery. Remote Sens. Environ. 2013, 129, 54-65. [CrossRef]

48. Meddens, A.J.; Hicke, J.A. Spatial and temporal patterns of Landsat-based detection of tree mortality caused by a mountain pine beetle outbreak in Colorado, USA. For. Ecol. Manag. 2014, 322, 78-88. [CrossRef]

49. Havašová, M.; Bucha, T.; Ferenčík, J.; Jakuš, R. Applicability of a vegetation indices-based method to map bark beetle outbreaks in the High Tatra Mountains. Ann. For. Res. 2015, 58, 295-310. [CrossRef]

50. Goodwin, N.R.; Coops, N.C.; Wulder, M.A.; Gillanders, S.; Schroeder, T.A.; Nelson, T. Estimation of insect infestation dynamics using a temporal sequence of Landsat data. Remote Sens. Environ. 2008, 112, 3680-3689. [CrossRef]

51. Eitel, J.U.; Vierling, L.A.; Litvak, M.E.; Long, D.S.; Schulthess, U.; Ager, A.A.; Krofcheck, D.J.; Stoscheck, L. Broadband, red-edge information from satellites improves early stress detection in a New Mexico conifer woodland. Remote Sens. Environ. 2011, 115, 3640-3646, doi:10.1016/j.rse.2011.09.002. [CrossRef]

52. Hewitt, A.E. New Zealand Soil Classification, 3rd ed.; Landcare Research Science Series No. 1; Manaaki Whenua Press: Lincoln, New Zealand, 2010.

53. Smith, G.M.; Milton, E.J. The use of the empirical line method to calibrate remotely sensed data to reflectance. Int. J. Remote Sens. 1999, 20, 2653-2662, doi:10.1080/014311699211994. [CrossRef]

54. Furby, S.L.; Campbell, N.A. Calibrating images from different dates to 'like-value' digital counts. Remote Sens. Environ. 2001, 77, 186-196, doi:10.1016/S0034-4257(01)00205-X. [CrossRef] 
55. Wang, J.; Rich, P.M.; Price, K.P.; Kettle, W.D. Relations between NDVI and tree productivity in the central Great Plains. Int. J. Remote Sens. 2004, 25, 3127-3138, doi:10.1080/0143116032000160499. [CrossRef]

56. Goetz, S.J.; Wright, R.K.; Smith, A.J.; Zinecker, E.; Schaub, E. IKONOS imagery for resource management: Tree cover, impervious surfaces, and riparian buffer analyses in the mid-Atlantic region. Remote Sens. Environ. 2003, 88, 195-208, doi:10.1016/j.rse.2003.07.010. [CrossRef]

57. Verbesselt, J.; Robinson, A.; Stone, C.; Culvenor, D. Forecasting tree mortality using change metrics derived from MODIS satellite data. For. Ecol. Manag. 2009, 258, 1166-1173, doi:10.1016/j.foreco.2009.06.011. [CrossRef]

58. Garcia-Ruiz, F.; Sankaran, S.; Maja, J.M.; Lee, W.S.; Rasmussen, J.; Ehsani, R. Comparison of two aerial imaging platforms for identification of Huanglongbing-infected citrus trees. Comput. Electron. Agric. 2013, 91, 106-115, doi:10.1016/j.compag.2012.12.002. [CrossRef]

59. Cunningham, S.C.; Read, J.; Baker, P.J.; Nally, R.M. Quantitative assessment of stand condition and its relationship to physiological stress in stands of Eucalyptus camaldulensis (Myrtaceae). Aust. J. Bot. 2007, 55, 692-699, doi:10.1071/BT07031. [CrossRef]

60. Rouse, J.W., Jr.; Haas, R.H.; Schell, J.A.; Deering, D.W. Monitoring Vegetation Systems in the Great Plains with ERTS. NASA Spec. Publ. 1974, 351, 309.

61. Gitelson, A.A.; Merzlyak, M.N. Remote sensing of chlorophyll concentration in higher plant leaves. Adv. Space Res. 1998, 22, 689-692, doi:10.1016/S0273-1177(97)01133-2. [CrossRef]

62. Gitelson, A.; Merzlyak, M.N. Spectral Reflectance Changes Associated with Autumn Senescence of Aesculus hippocastanum L. and Acer platanoides L. Leaves. Spectral Features and Relation to Chlorophyll Estimation. J. Plant Physiol. 1994, 143, 286-292, doi:10.1016/S0176-1617(11)81633-0. [CrossRef]

63. Sims, D.A.; Gamon, J.A. Relationships between leaf pigment content and spectral reflectance across a wide range of species, leaf structures and developmental stages. Remote Sens. Environ. 2002, 81, 337-354, doi:10.1016/S0034-4257(02)00010-X. [CrossRef]

64. Healey, S.P.; Cohen, W.B.; Zhiqiang, Y.; Krankina, O.N. Comparison of Tasseled Cap-based Landsat data structures for use in forest disturbance detection. Remote Sens. Environ. 2005, 97, 301-310, doi:10.1016/j.rse.2005.05.009. [CrossRef]

65. GDAL Development Team. GDAL-Geospatial Data Abstraction Library, Version 2.2.1; Open Source Geospatial Foundation: Beaverton, OR, USA, 2018.

66. Harvey, E.B.; Murthy, K. Forecasting manpower demand and supply: A model for the accounting profession in Canada. Int. J. Forecast. 1988, 4, 551-562, doi:10.1016/0169-2070(88)90132-X. [CrossRef]

67. Gao, Y.; Merz, C.; Lischeid, G.; Schneider, M. A review on missing hydrological data processing. Environ. Earth Sci. 2018, 77, 47, doi:10.1007/s12665-018-7228-6. [CrossRef]

68. Van Buuren, S.; Groothuis-Oudshoorn, K. Mice: Multivariate Imputation by Chained Equations in R. J. Stat. Softw. 2011, 45, 1-67, doi:10.18637/jss.v045.i03. [CrossRef]

69. Harrell, F.E., Jr.; Dupont, C. Hmisc: Harrell Miscellaneous; R Package Version 4.1-1; 2018. Available online: ftp:/ / sourceforge.mirror.ac.za/cran/web/packages/Hmisc/Hmisc.pdf (accessed on 17 June 2018).

70. Breiman, L. Random Forests. Mach. Learn. 2001, 45, 5-32, doi:10.1023/A:1010933404324. [CrossRef]

71. Stekhoven, D.J.; Bühlmann, P. MissForest-Non-parametric missing value imputation for mixed-type data. Bioinformatics 2012, 28, 112-118, doi:10.1093/bioinformatics/btr597. [CrossRef] [PubMed]

72. R Core Team. R: A Language and Environment for Statistical Computing; R Foundation for Statistical Computing: Vienna, Austria, 2017.

73. Dash, J.P.; Marshall, H.M.; Rawley, B. Methods for estimating multivariate stand yields and errors using k-NN and aerial laser scanning. Forestry 2015, 88, 237-247, doi:10.1093/forestry/cpu054. [CrossRef]

74. Dash, J.P.; Watt, M.S.; Bhandari, S.; Watt, P. Characterising forest structure using combinations of airborne laser scanning data, RapidEye satellite imagery and environmental variables. Forestry 2016, 89, 159-169, doi:10.1093/forestry/cpv048. [CrossRef]

75. Cutler, D.R.; Edwards, T.C.; Beard, K.H.; Cutler, A.; Hess, K.T.; Gibson, J.; Lawler, J.J. Random Forests for Classification in Ecology. Ecology 2007, 88, 2783-2792, doi:10.1890/07-0539.1. [CrossRef] [PubMed]

76. Mellor, A.; Haywood, A.; Stone, C.; Jones, S. The Performance of Random Forests in an Operational Setting for Large Area Sclerophyll Forest Classification. Remote Sens. 2013, 5, 2838, doi:10.3390/rs5062838. [CrossRef] 
77. Criminisi, A.; Shotton, J.; Konukoglu, E. Decision Forests: A Unified Framework for Classification, Regression, Density Estimation, Manifold Learning and Semi-Supervised Learning; NOW Publishers: Delft, The Netherlands, 2012.

78. Dash, J.P.; Pearse, G.D.; Watt, M.S.; Paul, T. Combining Airborne Laser Scanning and Aerial Imagery Enhances Echo Classification for Invasive Conifer Detection. Remote Sens. 2017, 9, 156, doi:10.3390/rs9020156. [CrossRef]

79. Liaw, A.; Wiener, M. Classification and Regression by randomForest. R News 2002, 2, 18-22.

80. Hothorn, T.; Buehlmann, P.; Dudoit, S.; Molinaro, A.; Van Der Laan, M. Survival Ensembles. Biostatistics 2006, 7, 355-373. [CrossRef] [PubMed]

81. Strobl, C.; Boulesteix, A.L.; Zeileis, A.; Hothorn, T. Bias in Random Forest Variable Importance Measures: Illustrations, Sources and a Solution. BMC Bioinform. 2007, 8, 25. [CrossRef] [PubMed]

82. Strobl, C.; Boulesteix, A.L.; Kneib, T.; Augustin, T.; Zeileis, A. Conditional Variable Importance for Random Forests. BMC Bioinform. 2008, 9, 307. [CrossRef] [PubMed]

83. Vollenweider, P.; Günthardt-Goerg, M.S. Diagnosis of abiotic and biotic stress factors using the visible symptoms in foliage. Environ. Pollut. 2005, 137, 455-465, doi:10.1016/j.envpol.2005.01.032. [CrossRef] [PubMed]

84. Blackburn, G.A. Hyperspectral remote sensing of plant pigments. J. Exp. Bot. 2007, 58, 855-867, doi:10.1093/jxb/erl123. [CrossRef] [PubMed]

85. Ustin, S.L.; Gitelson, A.; Jacquemoud, S.; Schaepman, M.; Asner, G.P.; Gamon, J.A.; Zarco-Tejada, P. Retrieval of foliar information about plant pigment systems from high resolution spectroscopy. Remote Sens. Environ. 2009, 113, S67-S77, doi:10.1016/j.rse.2008.10.019. [CrossRef]

86. Kokaly, R.F.; Asner, G.P.; Ollinger, S.V.; Martin, M.E.; Wessman, C.A. Characterizing canopy biochemistry from imaging spectroscopy and its application to ecosystem studies. Remote Sens. Environ. 2009, 113, S78-S91, doi:10.1016/j.rse.2008.10.018. [CrossRef]

87. Croft, H.; Chen, J.; Zhang, Y.; Simic, A.; Noland, T.; Nesbitt, N.; Arabian, J. Evaluating leaf chlorophyll content prediction from multispectral remote sensing data within a physically-based modelling framework. ISPRS J. Photogramm. Remote Sens. 2015, 102, 85-95, doi:10.1016/j.isprsjprs.2015.01.008. [CrossRef]

88. Carter, G.A. Ratios of leaf reflectances in narrow wavebands as indicators of plant stress. Int. J. Remote Sens. 1994, 15, 697-703, doi:10.1080/01431169408954109. [CrossRef]

89. Gartner, M.H.; Veblen, T.T.; Leyk, S.; Wessman, C.A. Detection of mountain pine beetle-killed ponderosa pine in a heterogeneous landscape using high-resolution aerial imagery. Int. J. Remote Sens. 2015, 36, 5353-5372, doi:10.1080/01431161.2015.1095369. [CrossRef]

90. White, J.C.; Wulder, M.A.; Brooks, D.; Reich, R.; Wheate, R.D. Detection of red attack stage mountain pine beetle infestation with high spatial resolution satellite imagery. Remote Sens. Environ. 2005, 96, 340-351, doi:10.1016/j.rse.2005.03.007. [CrossRef]

91. Wulder, M.A.; Dymond, C.C.; White, J.C.; Leckie, D.G.; Carroll, A.L. Surveying mountain pine beetle damage of forests: A review of remote sensing opportunities. For. Ecol. Manag. 2006, 221, 27-41, doi:10.1016/j.foreco.2005.09.021. [CrossRef]

92. Dennison, P.E.; Brunelle, A.R.; Carter, V.A. Assessing canopy mortality during a mountain pine beetle outbreak using GeoEye-1 high spatial resolution satellite data. Remote Sens. Environ. 2010, 114, 2431-2435, doi:10.1016/j.rse.2010.05.018. [CrossRef]

93. Thorp, K.; Tian, L. A review on remote sensing of weeds in agriculture. Precis. Agric. 2004, 5, 477-508. [CrossRef]

94. Babst, F.; Esper, J.; Parlow, E. Landsat TM/ETM+ and tree-ring based assessment of spatiotemporal patterns of the autumnal moth (Epirrita autumnata) in northernmost Fennoscandia. Remote Sens. Environ. 2010, 114, 637-646. [CrossRef]

95. Jepsen, J.; Hagen, S.; Høgda, K.; Ims, R.; Karlsen, S.; Tømmervik, H.; Yoccoz, N. Monitoring the spatio-temporal dynamics of geometrid moth outbreaks in birch forest using MODIS-NDVI data. Remote Sens. Environ. 2009, 113, 1939-1947. [CrossRef]

96. Kharuk, V.; Ranson, K.; Im, S. Siberian silkmoth outbreak pattern analysis based on SPOT VEGETATION data. Int. J. Remote Sens. 2009, 30, 2377-2388. [CrossRef] 
97. Spruce, J.P.; Sader, S.; Ryan, R.E.; Smoot, J.; Kuper, P.; Ross, K.; Prados, D.; Russell, J.; Gasser, G.; McKellip, R.; et al. Assessment of MODIS NDVI time series data products for detecting forest defoliation by gypsy moth outbreaks. Remote Sens. Environ. 2011, 115, 427-437. [CrossRef]

98. Lottering, R.; Mutanga, O. Optimising the spatial resolution of WorldView-2 pan-sharpened imagery for predicting levels of Gonipterus scutellatus defoliation in KwaZulu-Natal, South Africa. ISPRS J. Photogramm. Remote Sens. 2016, 112, 13-22. [CrossRef]

99. Carter, G.A.; Knapp, A.K. Leaf Optical Properties in Higher Plants: Linking Spectral Characteristics to Stress and Chlorophyll Concentration. Am. J. Bot. 2001, 88, 677-684. [CrossRef] [PubMed]

100. Luther, J.E.; Carroll, A.L. Development of an Index of Balsam Fir Vigor by Foliar Spectral Reflectance. Remote Sens. Environ. 1999, 69, 241-252, doi:10.1016/S0034-4257(99)00016-4. [CrossRef]

101. Ismail, R.; Mutanga, O. Discriminating the early stages of Sirex noctilio infestation using classification tree ensembles and shortwave infrared bands. Int. J. Remote Sens. 2011, 32, 4249-4266, doi:10.1080/01431161.2010.486413. [CrossRef]

102. Franklin, S.; Wulder, M.; Skakun, R.; Carroll, A. Mountain pine beetle red-attack forest damage classification using stratified Landsat TM data in British Columbia, Canada. Photogramm. Eng. Remote Sens. 2003, 69, 283-288. [CrossRef]

103. Skakun, R.S.; Wulder, M.A.; Franklin, S.E. Sensitivity of the thematic mapper enhanced wetness difference index to detect mountain pine beetle red-attack damage. Remote Sens. Environ. 2003, 86, 433-443. [CrossRef]

104. Wulder, M.A.; White, J.C.; Coops, N.C.; Butson, C.R. Multi-temporal analysis of high spatial resolution imagery for disturbance monitoring. Remote Sens. Environ. 2008, 112, 2729-2740. [CrossRef]

(C) 2018 by the authors. Licensee MDPI, Basel, Switzerland. This article is an open access article distributed under the terms and conditions of the Creative Commons Attribution (CC BY) license (http:/ / creativecommons.org/licenses/by/4.0/). 